\title{
Translocação e redistribuição de enxofre em plantas de milho e de soja(1)
}

\author{
Davi José Silva( ${ }^{(2)}$, Víctor Hugo Alvarez Venegas ${ }^{(3)}$, Hugo Alberto Ruiz ${ }^{(3)}$ e Renato Sant'Anna(4)
}

Resumo - O objetivo deste trabalho foi estudar a translocação e a redistribuição de $\mathrm{S}$ pelo transporte acrópeto e basípeto em plantas de milho e de soja. Plantas das duas espécies foram cultivadas em solução nutritiva contendo ${ }^{35} \mathrm{~S}$ em casa de vegetação. $\mathrm{O}{ }^{35} \mathrm{~S}$ aplicado em uma única raiz foi prontamente absorvido e translocado para a parte aérea, assim como para as demais raízes cultivadas na ausência de enxofre. $\mathrm{O}$ radioisótopo aplicado em uma única folha foi transportado tanto na direção acrópeta quanto na basípeta. Entretanto, o milho e a soja mostraram comportamentos diferentes na absorção e na redistribuição do enxofre. O milho, apesar de ter apresentado maior absorção radicular, reteve grande parte desse elemento na raiz, enquanto a soja absorveu consideravelmente menos, porém apresentou maior eficiência de translocação. Nas plantas de soja, as folhas superiores, principalmente as mais novas, mostraram ser os principais drenos fisiológicos do enxofre.

Termos de indexação: Zea mays, Glycine max, transporte de nutrientes, raiz, absorção.

\section{Translocation and redistribution of sulphur in corn and soybean plants}

Abstract - The objective of this work was to study the S translocation and redistribution by acropetal and basipetal transport in corn and soybean plants. Plants of both species were cultivated in nutritive solution containing labeled ${ }^{35} \mathrm{~S}$, in a greenhouse. The ${ }^{35} \mathrm{~S}$ applied to only one root was absorbed quickly and transported to the shoot, as well as to the other roots cultivated in non-labeled solution. The ${ }^{35} \mathrm{~S}$ applied to only one leaf was transported both to acropetal and basipetal direction. However, corn and soybean showed different behaviors in $\mathrm{S}$ absorption and redistribution. In spite of having larger root absorption, corn retained great part of that $\mathrm{S}$ in the root, while soybean absorbed considerably less, but presented greater translocation efficiency. The upper leaves, mainly the youngest, showed to be the main physiologic sinks for $\mathrm{S}$ in soybean plants.

Index terms: Zea mays, Glycine max, nutrient transport, root, absorption.

\section{Introdução}

O íon sulfato é a principal forma de $\mathrm{S}$ absorvida pelas plantas (Salisbury \& Ross, 1992). Depois de ser absorvido, o sulfato é reduzido e incorporado em aminoácidos que são redistribuídos para as partes

\footnotetext{
(1) Aceito para publicação em 17 de março de 2003. Extraído da tese de doutorado apresentada pelo primeiro autor à Universidade Federal de Viçosa (UFV), Viçosa, MG. Parcialmente financiado pelo CNPq.

(2) Embrapa-Centro de Pesquisa Agropecuária do Trópico SemiÁrido, Caixa Postal 23, CEP 56302-970 Petrolina, PE. E-mail: davi@cpatsa.embrapa.br

(3) UFV, Dep. de Solos, Avenida P. H. Rolfs, s/no, CEP 36571-000 Viçosa, MG. Bolsista do CNPq E-mail:vhav@mail.ufv.br,hruiz@mail.ufv.br

(4) UFV, Dep. de Biologia.
}

da planta em crescimento (Herschbach \& Rennenberg, 1994). A absorção de sulfato pelas raízes é um processo ativo, dependente de energia (Cram, 1990), mediado por distintos transportadores de sulfato, que estão presentes em diferentes tipos de células (Herschbach \& Rennenberg, 2001).

O sulfato é translocado através do xilema para as folhas, onde é incorporado a esqueletos carbônicos. O transporte de sulfato pode ocorrer tanto no xilema quanto no floema, sendo prontamente trocável entre essas vias (Larsson et al., 1991).

Compostos contendo $S$ reduzido podem ser transportados na direção acrópeta para as folhas em desenvolvimento, assim como na direção basípeta para o caule e as raízes (Herschbach \& Rennenberg, 1995; Hartmann et al., 2000). Em algumas espécies de árvores, no entanto, o transporte de $\mathrm{S}$ reduzido no floema ocorre apenas na direção basípeta, não havendo 
transferência entre floema e xilema (Herschbach \& Rennenberg, 2001). A glutationa seria a principal forma de S reduzido transportada no floema (Garsed \& Read, 1977b; Herschbach \& Rennenberg, 2001).

O S pode ser absorvido diretamente pelas folhas em forma oxidada ou reduzida. A aplicação de ${ }^{35} \mathrm{~S}$-cisteína na folha de espécies arbóreas resultou em uma exportação de $0,3 \%$ a $1,2 \%$ do ${ }^{35} \mathrm{~S}$ para outras partes da planta em Fagus sylvatica (Herschbach \& Rennenberg, 1995) e de 54\% a 77\% em Piceas abies (Schneider et al., 1994). Em plantas de soja, a absorção, a assimilação e a redistribuição de $\mathrm{S}$ se processam com bastante rapidez, uma vez que se detectou sulfato marcado na solução nutritiva uma hora após a exposição das folhas ao ${ }^{35} \mathrm{SO}_{2}$ (Garsed \& Read, 1977a). O sulfato foi o principal composto marcado transportado no floema, seguido por menores quantidades de glutationa e cisteína (Garsed \& Read, 1977b).

A redistribuição do $\mathrm{S}$ na planta envolve a ciclagem do elemento por meio do sistema radicular. Isto foi demonstrado por Sunarpi \& Anderson (1998) em plantas de soja. No entanto, ainda não está esclarecido se ocorre a ciclagem de formas reduzidas de $\mathrm{S}$ (Herschbach \& Rennenberg, 2001).

A absorção de sulfato e o carregamento de sulfato no xilema são processos independentes, mediados por diferentes sistemas de transporte. O carregamento no xilema é controlado mais pela demanda da parte aérea do que pela absorção de S (Herschbach et al., 1995a, 1995b). A transferência de sulfato e de compostos contendo $\mathrm{S}$ reduzido entre o xilema e o floema é particularmente importante no transporte de $\mathrm{S}$, uma vez que esse nutriente é retido nas folhas velhas com maior intensidade do que em outras partes da planta. Clarkson et al. (1983) comentam que o floema deve ter uma capacidade considerável de transportar S, uma vez que a redução do sulfato ocorre, principalmente, nas folhas, e as raízes são amplamente dependentes dessa via de transporte para a aquisição de aminoácidos contendo enxofre. Contudo, a entrada de sulfato no floema é restrita e a sua manutenção nas folhas velhas, mesmo sob condições de estresse de $\mathrm{S}$, deve estar relacionada com esse fato. Essa imobilidade a partir das folhas velhas é um dos aspectos mais enigmáticos do papel do $\mathrm{S}$ na fisiologia da planta (Cram, 1990).
O objetivo deste trabalho foi estudar a translocação e a redistribuição de $\mathrm{S}$ pelo transporte acrópeto e basípeto, em plantas de milho e de soja.

\section{Material e Métodos}

Foram realizados dois ensaios, em casa de vegetação, utilizando-se plantas de milho (Zea mays L.), híbrido BR 201, e de soja (Glycine max (L.) Merrill), variedade UFV-2, no período de julho de 1992 a junho de 1993.

As sementes de milho e de soja foram germinadas em rolos de papel toalha, colocados em vasos de plástico contendo água desionizada e continuamente arejados. Após a emergência, as plântulas foram selecionadas quanto à uniformidade e transplantadas para caixas contendo $25 \mathrm{~L} \mathrm{de}$ solução nutritiva. As soluções utilizadas foram as de Foy et al. (1967), para o milho, e de Ruiz (1997), a meia força, para a soja (Tabela 1). O pH foi ajustado diariamente para 5,5 e as soluções foram continuamente arejadas.

No primeiro ensaio, a translocação e a redistribuição do $\mathrm{S}$ absorvido por parte do sistema radicular foram avaliadas $0,6,12$ e 24 horas após a absorção de ${ }^{35} \mathrm{~S}$ por uma única raiz. Vinte plantas de milho e 20 de soja com 11 e 15 dias de idade, e com cinco folhas e três folhas trifolioladas, respectivamente, foram submetidas a um pré-tratamento, em solução isenta de $\mathrm{S}$, por 48 horas.

Decorrido esse prazo, cada planta foi colocada em um sistema de vasos geminados. Em um dos vasos colocou-se um tubo de ensaio contendo solução de cultivo com $15 \mu \mathrm{mol} / \mathrm{L}$ de $\mathrm{S}$ marcado na forma de $\mathrm{Na}_{2}{ }^{35} \mathrm{SO}_{4}$. Nesse tubo foi colo-

Tabela 1. Fontes e concentração dos nutrientes da solução nutritiva utilizada no cultivo das plantas de milho e de soja.

\begin{tabular}{|c|c|c|c|}
\hline Fonte & $\begin{array}{c}\text { Concentração } \\
(\mathrm{mmol} / \mathrm{L})\end{array}$ & Fonte & $\begin{array}{c}\text { Concentração } \\
(\mu \mathrm{mol} / \mathrm{L})\end{array}$ \\
\hline \multicolumn{4}{|c|}{ Milho } \\
\hline $\mathrm{Ca}\left(\mathrm{NO}_{3}\right)_{2} \cdot 4 \mathrm{H}_{2} \mathrm{O}$ & 1,27 & $\mathrm{H}_{3} \mathrm{BO}_{3}$ & 6,47 \\
\hline $\mathrm{Mg}\left(\mathrm{NO}_{3}\right)_{2} \cdot 6 \mathrm{H}_{2} \mathrm{O}$ & 0,27 & $\mathrm{ZnSO}_{4} \cdot 7 \mathrm{H}_{2} \mathrm{O}^{(1)}$ & 0,61 \\
\hline $\mathrm{NH}_{4} \mathrm{NO}_{3}$ & 0,30 & $\mathrm{MnCl}_{2} \cdot 4 \mathrm{H}_{2} \mathrm{O}$ & 2,36 \\
\hline $\mathrm{KNO}_{3}$ & 0,33 & $\mathrm{CuSO}_{4} .5 \mathrm{H}_{2} \mathrm{O}^{(1)}$ & 0,16 \\
\hline $\mathrm{KH}_{2} \mathrm{PO}_{4}$ & 0,10 & $\mathrm{Na}_{2} \mathrm{MoO}_{4} \cdot 2 \mathrm{H}_{2} \mathrm{O}$ & 0,05 \\
\hline $\mathrm{K}_{2} \mathrm{SO}_{4}^{(2)}$ & 0,12 & FeEDTA & 75,00 \\
\hline $\mathrm{KCl}$ & 0,17 & & \\
\hline \multicolumn{4}{|c|}{ Soja } \\
\hline $\mathrm{NH}_{4} \mathrm{H}_{2} \mathrm{PO}_{4}$ & 0,35 & $\mathrm{H}_{3} \mathrm{BO}_{3}$ & 9,5 \\
\hline $\mathrm{Ca}\left(\mathrm{NO}_{3}\right)_{2} \cdot 4 \mathrm{H}_{2} \mathrm{O}$ & 0,90 & $\mathrm{ZnSO}_{4} \cdot 7 \mathrm{H}_{2} \mathrm{O}^{(1)}$ & 1,0 \\
\hline $\mathrm{MgSO}_{4} \cdot 7 \mathrm{H}_{2} \mathrm{O}^{(3)}$ & 0,10 & $\mathrm{MnCl}_{2} \cdot 4 \mathrm{H}_{2} \mathrm{O}$ & 3,5 \\
\hline \multirow{4}{*}{$\mathrm{KNO}_{3}$} & 0,50 & $\mathrm{CuSO}_{4} .5 \mathrm{H}_{2} \mathrm{O}^{(1)}$ & 0,25 \\
\hline & & $\left(\mathrm{NH}_{4}\right)_{6} \mathrm{Mo}_{7} \mathrm{O}_{24} \cdot 4 \mathrm{H}_{2} \mathrm{O}$ & 0,043 \\
\hline & & $\mathrm{FeCl}_{3} \cdot 6 \mathrm{H}_{2} \mathrm{O}$ & 40,0 \\
\hline & & $\mathrm{Na}_{2}$ EDTA & 40,0 \\
\hline
\end{tabular}

(1)Substituídos por $\mathrm{ZnCl}_{2}$ e $\mathrm{CuCl}_{2} \cdot 2 \mathrm{H}_{2} \mathrm{O}$, respectivamente. (2) $\mathrm{Na}$ solução de cultivo isenta de $\mathrm{S}$ este sal foi substituído por $\mathrm{KCl}$. ${ }^{(3)} \mathrm{Na}$ solução de cultivo isenta de $\mathrm{S}$ este sal foi substituído por $\mathrm{MgCl}_{2} \cdot 6 \mathrm{H}_{2} \mathrm{O}$. 
cada apenas uma raiz, ao passo que o restante do sistema radicular foi mergulhado numa solução nutritiva isenta de $\mathrm{S}$, que estava no outro vaso. O período de absorção foi de 24 horas. Durante esse tempo, as plantas permaneceram sob fluxo luminoso contínuo. $\mathrm{O}$ pH de todas as soluções nutritivas foi previamente ajustado para $5,5 \pm 0,2$.

Em cada planta, após o período de absorção de ${ }^{35} \mathrm{~S}$, o tubo de ensaio que continha a raiz mergulhada na solução marcada foi substituído por outro de mesma capacidade, contendo solução de cultivo não marcada e o restante do sistema radicular foi colocado em outra solução de cultivo isenta de enxofre. Dessa forma, as plantas tiveram 0, 6, 12 e 24 horas para a redistribuição do $\mathrm{S}$ marcado. Em cada tempo de redistribuição foram realizadas cinco repetições.

Terminado o período de redistribuição, as plantas foram retiradas dos vasos geminados e suas raízes lavadas em água corrente por 10 minutos. Em cada período de redistribuição, uma repetição foi utilizada na obtenção de auto-radiografias e as demais foram submetidas à digestão nítrico-perclórica.

O preparo das plantas para a auto-radiografia consistiu em lavar as raízes por 10 minutos em água corrente e, em seguida, secá-las com papel absorvente. Raízes e parte aérea foram separadas, colocadas em uma prensa de herbário e secadas em estufa a $60^{\circ} \mathrm{C}$, por 24 horas. Ao final desse procedimento, o sistema radicular e a parte aérea foram montados separadamente sobre placas de isopor de $24 \times 30 \mathrm{~cm}$. Por intermédio de um contador Guiger Muller de janela fina foram efetuadas observações da atividade radioisotópica na superfície do material vegetal, através de um orifício de $1 \mathrm{~cm}^{2}$ de área. A partir da média geral das observações realizadas determinou-se o tempo de exposição do material vegetal ao filme radiográfico, como sendo o tempo necessário para que ocorressem $1,8.10^{7}$ desintegrações $/ \mathrm{cm}^{2}$. O filme de raios-X foi colocado em contato direto com a parte superior da montagem e introduzido num envelope preto, no interior de uma câmara escura. Transcorrido o tempo de exposição adequado (10,4 e 19 horas para raízes e parte aérea, respectivamente), o filme de raios-X foi retirado do envelope e, ainda na câmara escura, efetuou-se imediatamente a sua revelação.

O preparo para a digestão nítrico-perclórica consistiu em lavar as raízes por 10 minutos em água desionizada e, em seguida, secá-las com papel absorvente. Raízes, caule, folhas superiores e inferiores foram separadas e secadas em estufa a $70^{\circ} \mathrm{C}$ até peso constante. A seguir, todo o material vegetal foi mineralizado por digestão nítrico-perclórica e, no extrato obtido, procedeu-se a determinação da atividade do ${ }^{35} \mathrm{~S}$ por espectrometria de cintilação líquida.

No segundo ensaio, a redistribuição do $\mathrm{S}$ absorvido pelas folhas foi avaliada 6, 12, 24 e 48 horas após a aplicação de ${ }^{35}$ S. Vinte plantas de milho e 20 de soja com 10 e
17 dias de idade, apresentando cinco folhas e três folhas trifolioladas, respectivamente, foram transferidas para vasos com 1,5 L de solução nutritiva isenta de S, 48 horas antes da aplicação do radioisótopo. As soluções foram continuamente arejadas e o $\mathrm{pH}$ foi corrigido, diariamente, para $5,5 \pm 0,2$.

A solução a ser aplicada às folhas foi preparada misturando-se uma solução de $\mathrm{Na}_{2}{ }^{35} \mathrm{SO}_{4}$ com o espalhante-adesivo Triton X-100 e foi aplicada às folhas por meio de um pincel. Foram pinceladas pequenas quantidades na superfície adaxial da lâmina foliar da terceira folha da planta de milho e do folíolo central da segunda folha trifoliada da planta de soja. A solução foi aplicada nas primeiras horas da manhã, sendo a temperatura ambiente mantida em $27^{\circ} \mathrm{C}$ e $22^{\circ} \mathrm{C}$ nos períodos do dia e da noite, respectivamente. O número de horas de luz ficou em torno de 12 horas/dia. Contudo, a luminosidade não foi controlada, uma vez que as plantas foram cultivadas sob luz natural.

Antes da aplicação foliar do ${ }^{35} \mathrm{~S}$, as soluções nutritivas foram substituídas por outras também isentas de $\mathrm{S}$, com o $\mathrm{pH}$ previamente ajustado para 5,5 , sendo o arejamento mantido constante durante o estudo. Foram realizadas cinco repetições para cada tempo de redistribuição.

Em cada período de redistribuição, uma das repetições foi preparada para a auto-radiografia, enquanto as demais foram preparadas e submetidas à digestão nítricoperclórica. O preparo do material vegetal para análise, assim como o cálculo do tempo de exposição às chapas radiográficas, foram realizados conforme métodos descritos no primeiro experimento.

\section{Resultados e Discussão}

$\mathrm{O}{ }^{35} \mathrm{~S}$ aplicado a uma única raiz foi prontamente absorvido e translocado para a parte aérea, assim como para as raízes que estavam na solução nutritiva isenta de enxofre. Quando se compara a fotografia com a auto-radiografia, observa-se que ocorreu acúmulo desuniforme de ${ }^{35} \mathrm{~S}$ entre os dois lados da nervura central das folhas de milho (Figura 1), pois a disponibilidade de ${ }^{35} \mathrm{~S}$ foi limitada a apenas parte do sistema radicular, refletindo a organização vascular das raízes e da parte aérea dessa planta.

Uma fração considerável do radionuclídeo absorvido foi mantida na raiz marcada das plantas de milho e de soja (Tabela 2). Uma fração menor foi transportada para a parte aérea e redistribuída para drenos situados em outras partes da planta. Esse comportamento também foi reportado por Smith \& Cheema (1985).

Pesq. agropec. bras., Brasília, v. 38, n. 6, p. 715-721, jun. 2003 
As plantas de milho retiveram maior proporção da radioatividade na raiz marcada, $82,4 \%$ em média, enquanto as plantas de soja foram capazes de translocar maior quantidade de $\mathrm{S}$, retendo, em média, $60,6 \%$ da radioatividade nessa raiz. Esse último resultado está de acordo com os encontrados por Clarkson et al. (1983), com plantas de siratro, que retiveram em torno de $60 \%$ do ${ }^{35} \mathrm{~S}$ absorvido por uma única raiz, translocando o restante, principalmente, para a parte aérea.

O milho, apesar de apresentar maior absorção de ${ }^{35} \mathrm{~S}$ por grama de matéria seca de raiz, retém a maior parte desse S na própria raiz, enquanto a soja absorve menos, porém transloca mais ${ }^{35} \mathrm{~S}$, retendo uma fração menor que a do milho nas raízes. Os baixos valores da atividade de ${ }^{35} \mathrm{~S}$ obtidos nas partes

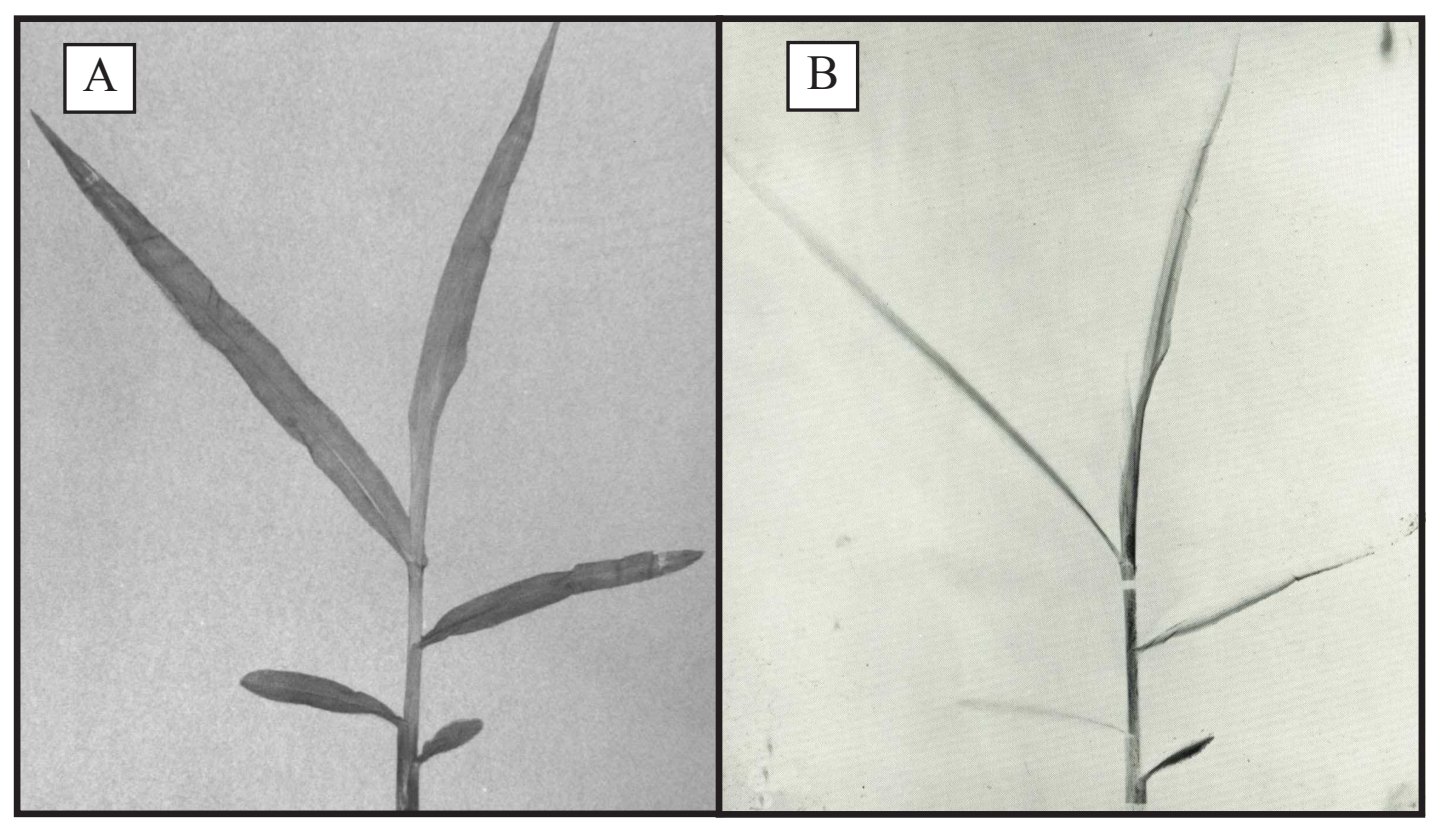

Figura 1. Fotografia (A) e auto-radiografia (B) da distribuição de ${ }^{35} \mathrm{~S}$ na parte aérea de uma planta de milho, 24 horas após a absorção do isótopo por uma única raiz.

Tabela 2. Atividade relativa de ${ }^{35} \mathrm{~S}$ na raiz marcada e nas partes receptoras das plantas de milho e de soja e distribuição porcentual da radioatividade entre as partes receptoras em razão do tempo de redistribuição do isótopo.

\begin{tabular}{|c|c|c|c|c|c|c|}
\hline \multirow{3}{*}{$\begin{array}{l}\text { Tempo de } \\
\text { redistribuição } \\
\text { (horas) }\end{array}$} & \multirow{2}{*}{$\begin{array}{c}\text { Raiz } \\
\text { marcada }\end{array}$} & \multirow{2}{*}{$\begin{array}{l}\text { Partes } \\
\text { receptoras }\end{array}$} & \multicolumn{4}{|c|}{ Parte receptora } \\
\hline & & & \multirow[t]{2}{*}{$\begin{array}{c}\text { Folhas } \\
\text { superiores }\end{array}$} & \multirow[t]{2}{*}{$\begin{array}{c}\text { Folhas } \\
\text { inferiores }\end{array}$} & Caule & \multirow{2}{*}{$\begin{array}{c}\text { Raízes } \\
\text { receptoras }\end{array}$} \\
\hline & \multicolumn{2}{|c|}{---------- (cpm/g de matéria seca) ---------- } & & & & \\
\hline & & & Milho & & & \\
\hline 0 & $4.515 .731(78,3 \%)^{(1)}$ & $1.251 .121(21,7 \%)$ & 14,5 & 2,1 & 62,3 & 21,1 \\
\hline 6 & $5.044 .135(84,7 \%)$ & $909.856(15,3 \%)$ & 17,2 & 7,0 & 52,5 & 23,3 \\
\hline 12 & $3.633 .141(79,1 \%)$ & $957.964(20,9 \%)$ & 19,5 & 4,9 & 49,8 & 25,8 \\
\hline 24 & $4.797 .420(87,5 \%)$ & $683.967(12,5 \%)$ & 22,9 & 2,7 & 42,1 & 32,3 \\
\hline & & & Soja & & & \\
\hline 0 & $1.419 .284(59,9 \%)$ & $948.188(40,1 \%)$ & 62,1 & 10,3 & 23,1 & 5,3 \\
\hline 6 & $1.192 .236(61,7 \%)$ & $738.795(38,3 \%)$ & 59,7 & 8,4 & 26,4 & 5,5 \\
\hline 12 & $1.370 .253(67,9 \%)$ & $647.755(32,1 \%)$ & 63,1 & 5,7 & 27,0 & 4,2 \\
\hline 24 & $988.354(53,0 \%)$ & $867.058(47,0 \%)$ & 60,1 & 14,5 & 18,0 & 7,3 \\
\hline
\end{tabular}


receptoras podem ser decorrentes do efluxo do radioisótopo para o meio, através das outras raízes receptoras, que foram cultivadas em solução isenta de enxofre.

Não existe uma tendência bem definida para a redistribuição do ${ }^{35} \mathrm{~S}$ em razão do tempo, nas diferentes partes da planta (Tabela 2). No milho, percebe-se que grande parte da radioatividade redistribuída a partir da raiz marcada foi encontrada no caule. Neste órgão, a atividade de ${ }^{35} \mathrm{~S}$ tende a diminuir com o aumento do tempo de redistribuição. As folhas superiores e as raízes receptoras apresentaram maior radioatividade com o aumento do tempo de redistribuição, indicando que essas partes da planta são drenos importantes para o enxofre. Nas plantas de soja, o $\mathrm{S}$ translocou-se, principalmente, para as folhas superiores. As folhas inferiores apresentaram baixa atividade de ${ }^{35} \mathrm{~S}$ e a radioatividade do caule tendeu a diminuir com o aumento do tempo de redistribuição. A radioatividade detectada na raiz marcada das plantas de soja foi menor que nas plantas de milho. Isso se deveu a uma menor absorção radicular ou a um efluxo mais intenso, pois a radioatividade redistribuída para as outras partes da planta foi da mesma ordem de grandeza que no milho.

Assim, a soja reteve maior proporção do ${ }^{35} \mathrm{~S}$ em suas folhas superiores, enquanto o milho o redistribuiu para outras partes da planta. O movimento basípeto de ${ }^{35} \mathrm{~S}$ ocorre, portanto, com maior intensidade nas plantas de milho do que nas plantas de soja. $\mathrm{O}$ acúmulo de $\mathrm{S}$ poderia ocorrer, tanto na forma de sulfato quanto de compostos contendo S reduzido, principalmente glutationa, em tecidos de reserva das folhas ou das raízes (Herschbach \& Rennenberg, 1995; Hartmann et al., 2000).

$\mathrm{O}{ }^{35} \mathrm{~S}$ aplicado às folhas foi transportado tanto na direção acrópeta quanto na basípeta nas plantas de milho e de soja (Figura 2). A aplicação foliar de ${ }^{35} \mathrm{~S}$ resultou em pronta absorção e rápida translocação do radioisótopo para todas as partes da planta (Tabela 3). Resultados semelhantes foram obtidos por Garsed \& Read (1977a, 1977b) ao aplicarem ${ }^{35} \mathrm{SO}_{2}$ à primeira folha trifoliada de plantas de soja.

Nas plantas de soja, a porcentagem de ${ }^{35} \mathrm{~S}$ absorvida e translocada para outras partes da planta é de aproximadamente $2 \%$, sendo de magnitude semelhante àquela obtida para as plantas de milho. Dessa for-

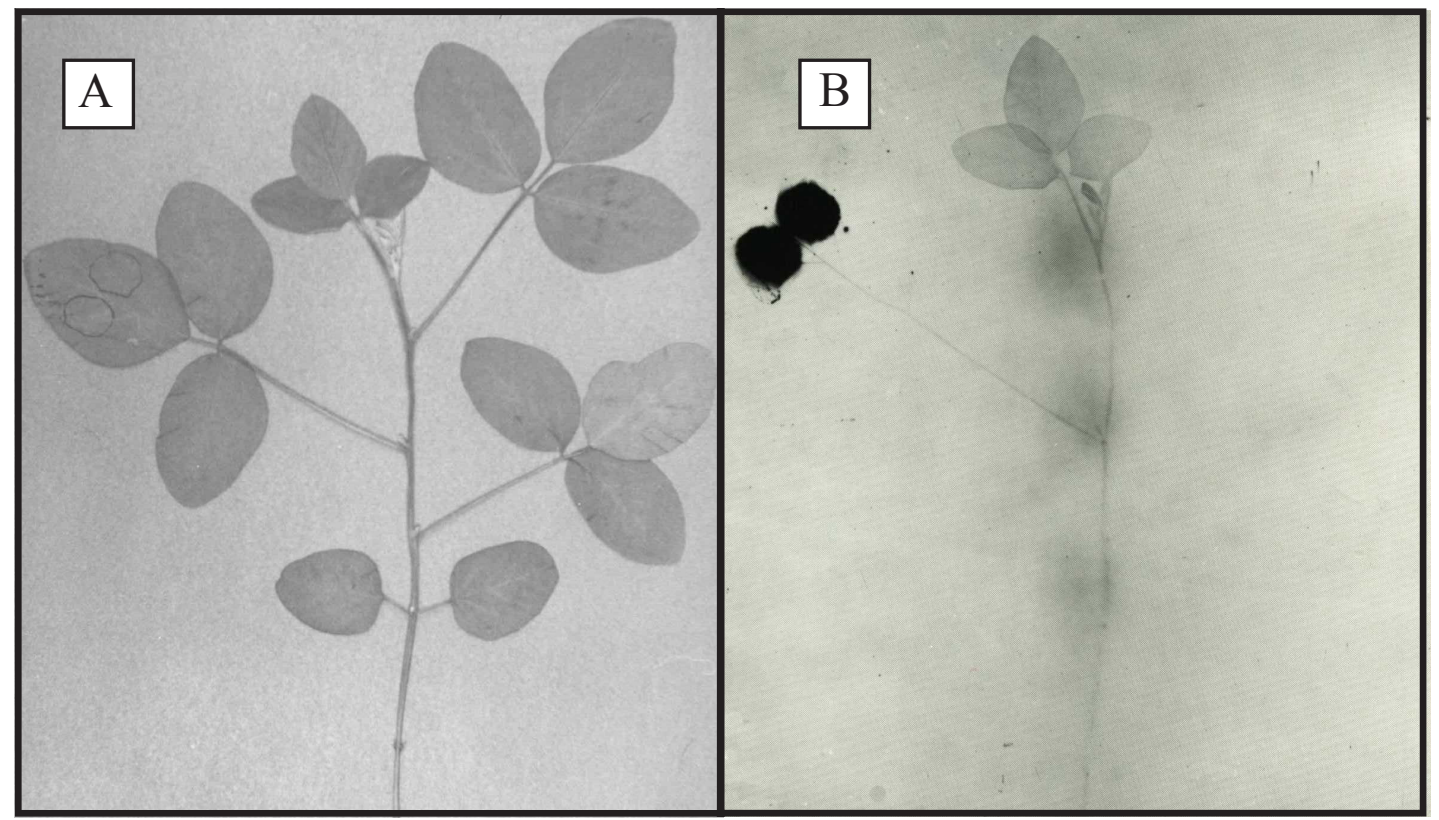

Figura 2. Fotografia (A) e auto-radiografia (B) da distribuição de ${ }^{35} \mathrm{~S}$ na parte aérea de uma planta de soja, 48 horas após a aplicação foliar do isótopo. As áreas circulares indicam os sítios de aplicação. 
ma, uma fração em torno de $98 \%$ do ${ }^{35} \mathrm{~S}$ foi mantida nas folhas de milho e de soja tratadas com a solução marcada (Tabela 3). Resultados semelhantes foram obtidos por Garsed \& Read (1977a).

Após seis horas da aplicação do ${ }^{35} \mathrm{~S}$, não houve efeito dos tempos de redistribuição sobre a absorção foliar do radioisótopo. Shaw et al. (1992) afirmam que a absorção foliar é dependente do tempo, podendo ser descrita por um modelo exponencial simples. Esses efeitos não foram observados nas plantas de milho e de soja, mesmo havendo diluição na atividade de ${ }^{35} \mathrm{~S}$ por grama de matéria seca nas folhas marcadas da soja, em virtude de uma maior produção de matéria seca dessas folhas em relação às de milho (Tabela 3).

Nas plantas de milho, o S foi transportado, preferencialmente, para as raízes e para o caule (Tabela 3 ). Nas primeiras horas de absorção foliar, ${ }^{35} \mathrm{~S}$ foi transportado, principalmente, para as raízes. Esse $\mathrm{S}$, possivelmente na forma de sulfato, foi retranslocado de maneira mais lenta para a parte aérea, onde pode ter sido reduzido e incorporado a esqueletos carbônicos nas folhas. Em plantas perenes, o transporte de compostos contendo $\mathrm{S}$ reduzido ocorreu em direção às partes basípetas do tronco em Fagus sylvatica (Herschbach \& Rennenberg, 1995) e em direção ao ápice das acículas em Piceas abies (Schneider et al., 1994), após a aplicação de ${ }^{35} \mathrm{~S}$ a uma folha madura dessas espécies.

As plantas de soja apresentaram transporte acrópeto de ${ }^{35} \mathrm{~S}$ bastante intenso, principalmente para as folhas superiores. As folhas inferiores apresentaram os menores valores de radioatividade, demonstrando que, realmente, não são drenos físiológicos importantes para o enxofre. Esses resultados confirmam os de Garsed \& Read (1977a, 1977b), que observaram um pequeno acúmulo de ${ }^{35} \mathrm{~S}$ nas folhas primárias da soja, enquanto a segunda e a terceira folhas trifolioladas, assim como as folhas apicais, acumularam as maiores concentrações do material radioativo que foi aplicado à primeira folha trifoliada.

$\mathrm{Na}$ soja, após seis horas da aplicação do ${ }^{35} \mathrm{~S}$, parece não haver efeito do tempo de redistribuição sobre a radioatividade encontrada nas folhas, ao passo que no caule e nas raízes um pequeno gradiente pode ser percebido, com diminuição no caule e aumento nas raízes. Esse aumento pode ser causado pelos compostos orgânicos metabolizados na parte aérea e transportados para as raízes via floema (Garsed \& Read, 1977b).

A translocação de ${ }^{35} \mathrm{~S}$ aplicado em folhas de milho e de soja ocorre, portanto, em direção ao ápice da planta bem como em direção às raízes. Herschbach \& Rennenberg (1995) observaram que, em plantas de F. sylvatica, apenas $2,2 \%$ a $6,1 \%$ do ${ }^{35} \mathrm{~S}$ exportado de uma folha marcada foram encontrados nas partes apicais da árvore, 3,4\% a 5,4\% em galhos situados abaixo do local de aplicação e $64 \%$ a $77 \%$ no sentido basípeto, em direção ao tronco, casca e raízes, demonstrando que o ápice da parte aérea e os galhos não são drenos preferenciais de enxofre.

Tabela 3. Atividade relativa de ${ }^{35} \mathrm{~S}$ na folha marcada e nas partes receptoras das plantas de milho e de soja e distribuição porcentual da radioatividade entre as partes receptoras em razão do tempo de redistribuição do isótopo.

\begin{tabular}{|c|c|c|c|c|c|c|}
\hline \multirow{3}{*}{$\begin{array}{c}\text { Tempo de } \\
\text { redistribuição } \\
\text { (horas) }\end{array}$} & \multirow{2}{*}{$\begin{array}{l}\text { Folha } \\
\text { marcada }\end{array}$} & \multirow{2}{*}{$\begin{array}{l}\text { Partes } \\
\text { receptoras }\end{array}$} & \multicolumn{4}{|c|}{ Parte receptora } \\
\hline & & & $\begin{array}{c}\text { Folhas } \\
\text { superiores }\end{array}$ & $\begin{array}{l}\text { Folhas } \\
\text { inferiores }\end{array}$ & Caule & Raízes \\
\hline & \multirow{2}{*}{\multicolumn{6}{|c|}{---------- (cpm/g de matéria seca) ---------- }} \\
\hline & & & Milho & & & \\
\hline 6 & $21.891 .280(96,9 \%)^{(1)}$ & $701.577(3,1 \%)$ & 4,4 & 1,4 & 21,1 & 73,1 \\
\hline 12 & $22.557 .424(97,4 \%)$ & $595.954(2,6 \%)$ & 7,3 & 2,5 & 42,7 & 47,4 \\
\hline 24 & $23.901 .104(98,7 \%)$ & $313.617(1,3 \%)$ & 13,0 & 0,5 & 57,9 & 28,6 \\
\hline \multirow[t]{2}{*}{48} & $21.395 .888(98,9 \%)$ & $223.855(1,1 \%)$ & 17,6 & 7,5 & 49,7 & 25,1 \\
\hline & & & Soja & & & \\
\hline 6 & $13.301 .940(97,8 \%)$ & $298.491(2,2 \%)$ & 41,1 & 1,6 & 38,5 & 18,8 \\
\hline 12 & $13.182 .903(98,4 \%)$ & $211.274(1,6 \%)$ & 40,9 & 1,9 & 35,7 & 21,5 \\
\hline 24 & $14.147 .284(97,8 \%)$ & $312.107(2,2 \%)$ & 43,7 & 1,2 & 30,3 & 24,8 \\
\hline 48 & $11.633 .300(97,3 \%)$ & $325.046(2,7 \%)$ & 41,1 & 1,2 & 27,0 & 30,7 \\
\hline
\end{tabular}

(1)Porcentual em relação à atividade total na planta. 


\section{Conclusões}

1. O S aplicado a uma única raiz é prontamente absorvido e translocado tanto para a parte aérea quanto para as outras raízes cultivadas na ausência de enxofre.

2. Plantas de milho apresentam maior absorção radicular de $\mathrm{S}$ que as de soja, retendo grande parte desse nutriente na própria raiz.

3. O enxofre aplicado a uma folha é transportado tanto na direção acrópeta quanto na basípeta.

4. Em plantas de milho, o S absorvido pela folha é transportado, preferencialmente, para o caule e para as raízes.

5. Nas plantas de soja, tanto o $\mathrm{S}$ absorvido pela raiz quanto pela folha é transportado, em maiores proporções, para as folhas superiores, não sendo redistribuído para outras partes da planta.

\section{Referências}

CLARKSON, D. T.; SMITH, F. W.; BERG, P. J. vanden. Regulation of sulfate transport in a tropical legume, Macroptilium atropurpureum, cv. Siratro. Journal of Experimental Botany, Oxford, v. 34, p. 1463-1483, 1983.

CRAM, W. J. Uptake and transport of sulfate. In: RENNENBERG, H.; BRUNOLD, C.; DE KOK, L. J.; STULEN, I. (Ed.). Sulfur nutrition and sulfur assimilation in higher plants: fundamental, environmental and agricultural aspects. The Hague: SPB Academic, 1990. p. 3-11.

FOY, C. D.; FLEMING, A. L.; BURNS, G. P.; ARMINGER, W. H. Characterization of differential aluminum tolerance among varieties of wheat and barley. Soil Science Society of America Proceedings, Madison, v. 31, p. $513-521,1967$

GARSED, S. G.; READ, D. J. Sulfur dioxide metabolism in soybean, Glycine max var. Beloxi - I: the effects of light and dark on the uptake and translocation of ${ }^{35} \mathrm{SO}_{2}$. New Phytologist, Cambridge, Inglaterra, v. 78, p. 111-119, 1977a.

GARSED, S. G.; READ, D. J. Sulfur dioxide metabolism in soybean, Glycine max var. Beloxi - II: biochemical distribution of ${ }^{35} \mathrm{SO}_{2}$ products. New Phytologist, Cambridge, Inglaterra, v. 79, p. 583-592, 1977b.

HARTMANN, T.; MULT S.; SUTER, M.; RENNENBERG, H.; HERSCHBACH, C. Leaf agedependent differences in sulfur assimilation and allocation in poplar (Populus tremula x P. alba) leaves. Journal of Experimental Botany, Oxford, v. 51, p. 1077-1088, 2000.
HERSCHBACH, C.; DE KOK, L. J.; RENNENBERG, $\mathrm{H}$. Net uptake of sulphate and its transport to shoot in spinach plants fumigated with $\mathrm{H}_{2} \mathrm{~S}$ or $\mathrm{SO}_{2}$. Does atmospheric sulfur affect the "inter-organ" regulation of sulfur nutrition? Botanica Acta, Stuttgart, v. 108, p. 41-46, 1995a.

HERSCHBACH, C.; DE KOK, L. J.; RENNENBERG, $\mathrm{H}$. Net uptake of sulphate and its transport to shoot in tobacco plants fumigated with $\mathrm{H}_{2} \mathrm{~S}$ or $\mathrm{SO}_{2}$. Plant and Soil, Dordrecht, v. 175 , n. 1, p. 75-84, Aug. 1995 b.

HERSCHBACH, C.; RENNENBERG, H. Influence of glutathione (GSH) on net uptake of sulfate and its transport in tobacco plants. Journal of Experimental Botany, Oxford, v. 45, p. 1069-1079, 1994.

HERSCHBACH, C.; RENNENBERG, H. Long-distance transport of ${ }^{35} \mathrm{~S}$-sulphur in 3-year-old beech trees (Fagus sylvatica). Physiologia Plantarum, Copenhagen, v. 95, n. 3, p. 379-386, Nov. 1995.

HERSCHBACH, C.; RENNENBERG, H. Sulfur nutrition of deciduous trees. Naturwissenschaften, Berlin, v. 88 , p. 25-36, 2001.

LARSSON, C. M.; LARSSON, M.; PURVES, J. V.; CLARKSON, D. T. Translocation and cycling through roots of recently absorbed nitrogen and sulfur in wheat (Triticum aestivum) during vegetative and generative growth. Physiologia Plantarum, Copenhagen, v. 82, p. 345-352, 1991.

RUIZ, H. A. Relações molares de macronutrientes em tecidos vegetais como base para a formulação de soluções nutritivas. Revista Ceres, Viçosa, MG, v. 44, n. 255 , p. $533-546,1997$.

SALISBURY, F. B.; ROSS, C. W. Plant physiology. $4^{\text {th }}$ ed. Belmond: Wadsworth, 1992. $682 \mathrm{p}$.

SCHNEIDER, A.; SCHATTEN, T.; RENNENBERG, H. Exchange between phloem and xylem during long-distance transport of glutathione in spruce trees (Picea abies [Karst.] L.). Journal of Experimental Botany, Oxford, v. 45 , p. $457-462,1994$.

SHAW, G.; MINSKI, M. J.; BELL, J. N. B. Retention, loss and translocation of radionuclides applied to foliar surfaces of wheat. Environmental and Experimental Botany, Oxford, v. 32, p. 391-401, 1992.

SMITH, I. K.; CHEEMA, H. K. Sulphate transport into plants and excised roots of soybean (Glycine $\max \mathrm{L}$.). Annals of Botany, London, v. 56, 219-224, 1985.

SUNARPI; ANDERSON, J. W. Direct evidence for the involvement of the root in the redistribution of sulfur between leaves. Journal of Plant Nutrition, New York, v. 21, n. 6 , p. $1273-1286,1998$. 